\title{
杜瓦苯与苯的共振结构
}

杨占会*，沈旭凡

北京化工大学化学学院, 有机化学系, 北京 100029

摘要: 苯的共振结构是有机化学教学的基础内容。国内不同版本教材在介绍这方面知识时, 并没有采用统一的说法。 本文建议国内部分教材在再版时考虑将杜瓦苯和其他离子结构从苯的共振结构中移除, 统一采用只包含两个单双键 交替的正六边形结构式的正确共振式。

关键词: 有机化学; 苯; 共振结构; 凯库勒式; 杜瓦苯

中图分类号：G64; O64；G41

\section{Dewar Benzene and the Resonance Structures of Benzene}

\section{Zhanhui Yang ${ }^{*}$, Xufan Shen}

Department of Organic Chemistry, College of Chemistry, Beijing University of Chemical Technology, Beijing 100029, China.

Abstract: The domestic organic chemistry textbooks use different numbers of contributing structures when introducing the resonance structures of benzene. This paper suggests that some of the related textbooks remove Dewar benzene and other ionic structures from the resonance structures of benzene, and adopt the correct resonance representation which constitutes only two Kekulé structures.

Key Words: Organic chemistry; Benzene; Resonance structure; Kekulé structure; Dewar bezene

苯的共振结构是有机化学教学的基础内容, 在解释苯的化学性质方面有着重要作用。国内不同 版本教材在介绍这方面内容时, 并没有统一的说法, 而是处于 “三家争鸣” 的状态。有的教材 ${ }^{[1-11] 认 ~}$ 为, 苯共振于两个单双键交替的正六边形极限结构式(i和ii, 图 1a); 有的教材 ${ }^{[12-21]}$ 认为, 除了结构式

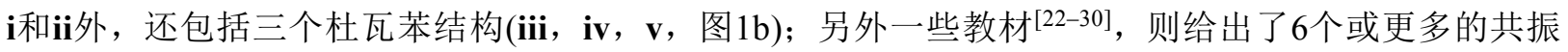
结构(图1c)。这些教材在有机化学领域都具有重要地位, 分别被不同高校使用, 产生了广泛的影响。

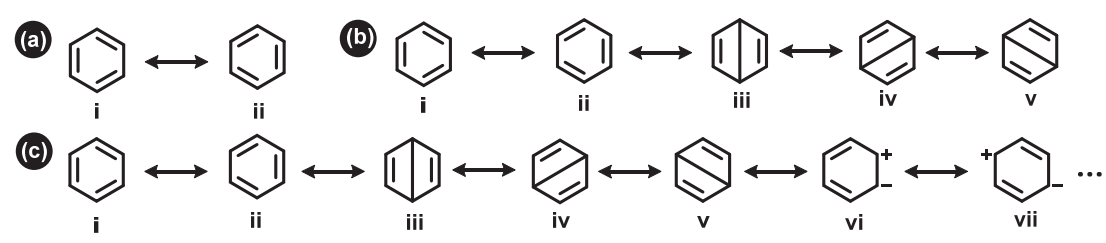

图1 现行国内教材关于苯的共振结构的三种讨论 有的教材将i和ii认为是凯库勒式 $[2,43,44,46,47]$, 有的教材明确指出它们不是凯库勒式 $[4,40,45]$, 最近有文献认为应该将它们命名为苯的Pauling结构式或Pauling苯 ${ }^{[31]}$

收稿: 2020-08-07; 录用: 2020-10-09; 网络发表: 2020-11-13

“通讯作者, Email: zhyang@mail.buct.edu.cn

项目资助: 北京化工大学有机化学优秀本科育人团队项目 
正因为此, 它们在苯的共振结构处理上的不统一, 给学习和教学带来了一定的困惑。这三种共振式 的核心问题是: 杜瓦苯是否应该列为苯的共振结构? 本文通过对苯的共振结构发展历史做简要介绍, 梳理出国际学术界主流的观点。

苯环的共振结构是百年来分子结构理论发展的结果 ${ }^{[32,33]}$ 。1931年, Pauling在前人的基础上提出 了共振理论 ${ }^{[34]}$, 并在1933年将其应用到苯环的结构解释上 ${ }^{[35]}$ 。根据Pauling和Wheland的计算结果, 苯环 的稳定性来自五个经典结构(两个凯库勒结构式和三个杜瓦苯结构式)的共振(式1b)。在当时的历史背 景下, 杜瓦苯的结构依然停留在猜想阶段, 尚未有确切的关于其真实结构的实验证据。而Paulding等 人的计算结果, 是基于杜瓦苯是平面结构这一猜想而得出的。作为共振论的首创者、权威量子化学 家和诺贝尔化学奖得主, Pauling关于苯共振结构的计算结果在全世界获得了广泛认可, 产生了巨大 影响。对Pauling结果的质疑始自1962年。该年, 威斯康星大学麦迪逊分校的van Tamelen和Pappas成 功制备出了第一个杜瓦苯结构—— “三叔丁基杜瓦苯” (2) (图2a) ${ }^{[36]}$, 并于次年成功制得 “无取代杜 瓦苯” (5) (图2b) ${ }^{[37]}$ 。他们对这两个物质的结构和化学性质进行了研究, 发现: 它们都不具有平面结 构, 两个环丁烯单元之间存在二面角; 分子具有很大的环张力, 化学性质活泼。例如, “三叔丁基 杜瓦苯” (2)在 $200{ }^{\circ} \mathrm{C}$ 下加热 $15 \mathrm{~min}$, 可高产率生成三叔丁基苯(1) (图2a) ${ }^{[36]}$; “无取代杜瓦苯” (5)在 $90^{\circ} \mathrm{C}$ 下加热 $15 \mathrm{~min}$, 可定量转化为苯 (6), 且其在室温下的半衰期约为 2 天(图 $\left.2 \mathrm{~b}\right)^{[37]}$ 。共振论要求: 若干共振结构在电子流动的同时, 原子核空间位置必须保持不变, 为同一物质的不同价键结构。对 比苯和杜瓦苯, 原子空间位置已经发生改变, 因此将其作为苯的共振结构是完全错误的。上述实验 证据还表明, 杜瓦苯是不同于苯的一类物质(二环[2.2.0]环己-2,5-二烯), 与棱晶烷、盆苯等结构一样, 为苯的价键异构体 ${ }^{[37]}$ 。事实上, Pauling等人关于苯的共振结构的计算本身就存在问题, 因为根据他 们的计算, 环丁二烯应该比苯环更稳定, 可事实却恰恰相反 ${ }^{[32,35]}$ 。

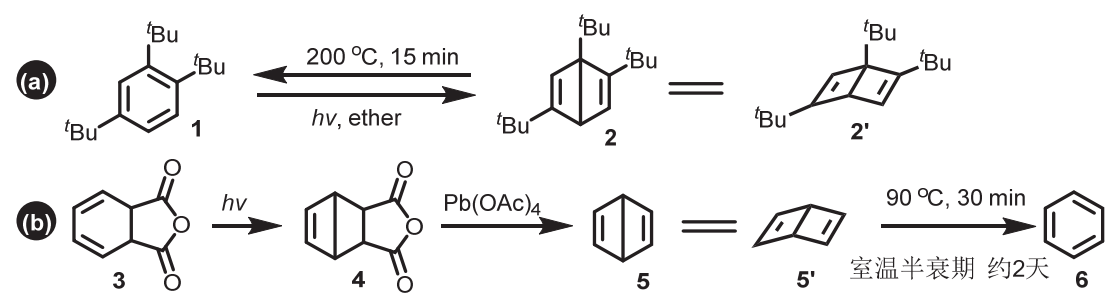

图2 杜瓦苯的制备及其结构

在事实证据面前 ${ }^{[36-39]}$, 国际学术界对Pauling提出的苯的共振式进行了修正, 不再将杜瓦苯作为 苯的共振结构。英文教学期刊和教科书统一采用了该修正理论 ${ }^{[32,40-48]}$, 而国内学术教育界则对该知 识更新较慢, 且没有形成统一的认识。田瑞亭在2001年就明确指出, “把狄瓦尔苯作为苯的共振式 是错误的, 应纠正” [49]。然而, 时至今日, 国内依然有相当一部分现行教材 ${ }^{[12-30]}$, 还在沿用Pauling 在1933年得出的错误论断。这既不利于学生的学习, 也不利于知识的正确传播。本文建议国内相关 教材在再版时与国际接轨, 统一采用图1a所示的只包含两个单双键交替的正六边形极限式的正确共 振式。

\section{参 考 文 献}

[1] 古练权, 汪波, 黄志纾, 吴云东. 有机化学. 北京: 高等教育出版社, 2008: 94.

[2] 邢其毅, 裴伟伟, 徐瑞秋, 裴坚. 基础有机化学. 第4版. 北京: 北京大学出版社, 2016: 402, 712 .

[3] 魏荣宝. 高等有机化学. 北京: 高等教育出版社, 2007: 3.

[4] 胡宏纹. 有机化学. 第4版. 北京: 高等教育出版社, 2014: 194.

[5] 伍越睘, 李伟甫, 沈晓明. 有机化学(修订版). 合肥: 中国科学技术大学出版社, 2002: 170. 
[6] 陆国元. 有机化学. 第3版. 南京: 南京大学出版社, 2018: 83 .

[7] 王积涛, 王永梅, 张宝申, 胡青眉, 庞美丽. 有机化学. 第3版. 天津: 南开大学出版社, 2009: 142.

[8] 陆阳, 申东升. 有机化学. 第2版. 北京: 科学出版社, 2017: 96-98.

[9] 王全瑞. 有机化学. 第2版. 北京: 化学工业出版社, 2018: 87-91.

[10] 郭书好, 李毅群. 有机化学. 北京: 清华大学出版社, 2007: 96.

[11] 罗一鸣. 有机化学. 北京: 化学工业出版社, 2013: 94.

[12] 高占先. 有机化学. 第3版. 北京: 高等教育出版社, 2018: 192.

[13] 高占先, 姜文风，于丽梅. 有机化学简明教程. 北京: 高等教育出版社, 2011: 139.

[14] 张文勤, 郑觛, 马宁, 赵温涛. 有机化学. 第5版. 北京: 高等教育出版社, 2014: 157

[15] 鲁崇贤, 杜洪光. 有机化学. 第2版. 北京: 科学出版社, 2009: 8 .

[16] 徐伟亮. 有机化学. 北京: 科学出版社, 2008: 91.

[17] 胡春. 有机化学. 北京: 高等教育出版社, 2013: 194.

[18] 王兴明, 康明. 基础有机化学. 第2版. 北京: 科学出版社, 2015: 138.

[19] 黄怡. 有机化学. 北京: 科学出版社, 2018: 113 .

[20] 龙跃, 杨贯羽. 有机化学. 北京: 高等教育出版社, 2016: 84 .

[21] 谷亨杰, 张力学, 丁金昌. 有机化学. 第3版. 北京: 高等教育出版社, 2016: 153 .

[22] 李艳梅, 赵圣印, 王兰英. 有机化学. 第2版. 北京: 科学出版社, 2014: 80 .

[23] 徐寿昌, 有机化学. 第2版. 北京: 高等教育出版社, 2014: 117.

[24] 尹冬冬. 有机化学. 北京: 高等教育出版社, 2010: 118.

[25] 薛思佳. 有机化学. 第2版. 北京: 科学出版社, 2015: 119.

[26] 孙国峰, 张元勤, 张海连, 曾鸿耀. 有机化学. 北京: 科学出版社, 2012: 126.

[27] 史达清, 赵蓓. 有机化学. 北京: 高等教育出版社, 2019: 167.

[28] 刘庆俭. 有机化学. 上海: 同济大学出版社, 2018: 218.

[29] 秦永其, 田海玲. 有机化学. 北京: 化学工业出版社, 2018: 70 .

[30] 李小瑞. 有机化学. 第2版. 北京: 化学工业出版社, 2018: 151.

[31] 杨占会, 沈旭凡. 大学化学, 2021, in press. doi: 10.3866/PKU.DXHX202009012

[32] Kikuchi, S. J. Chem. Ed. 1997, 74, 194.

[33] 百度百科. [2020-11-13]. https://baike.baidu.com/item/\%E8\%8B\%AF\%E7\%8E\%AF/7907286?fr=aladdin

[34] Pauling, L. J. Am. Chem. Soc. 1931, 53, 3225.

[35] Pauling, L.; Wheland, G. W. J. Chem. Phys. 1933, 1, 362.

[36] van Tamelen, E. E.; Pappas, S. P. J. Am. Chem. Soc. 1962, 84 , 37891.

[37] van Tamelen, E. E.; Pappas, S. P. J. Am. Chem. Soc. 1963, 85, 3297.

[38] van Tamelen, E. E. Acc. Chem. Res. 1972, 5, 186.

[39] Criegee, R.; Gruner, H. Angew. Chem. Int. Ed. 1968, 7, 467.

[40] Vollhardt, P. K.; Schore, N. Organic Chemistry: Structure and Function, 8th ed.; W. H. Freeman and Company: New York, NY, USA, 2018 ; p. 701.

[41] Solomans, T. W. G. Organic Chemistry, 4th ed.; John Wiley \& Sons, Inc.: New York, NY, USA, 1988; p. 492.

[42] McMurry, J. Organic Chemistry, 9th ed.; Cengage Learning: Boston, MA, USA, 2016; p. 458.

[43] Wade, L.G., Jr. Organic Chemistry, 8th ed.; Pearson Education, Inc.: Glenview, IL, USA, 2013; p. 714.

[44] Brown, W. H.; Iverson, B. L.; Anslyn, E. V.; Foote, C. S.; Novak, B. M. Organic Chemistry, 8th ed.; Cengage Learning: Boston, MA, USA, 2018 ; p. 942.

[45] Clayden, J.; Greeves, N.; Warren, S. Organic Chemistry, 2rd ed.; Oxford University Press Inc.: New York, NY, USA, 2012; p. 473.

[46] Carey, F. A.; Giuliano, R. M. Organic Chemistry, 10th ed.; McGraw-Hill Education: New York, NY, USA, 2017; p. 416.

[47] Klein, D. Organic Chemistry, 2rd ed.; John Wiley Sons, Inc.: Hoboken, GA, USA, 2015; p. 838.

[48] Chaloner, P. Organic Chemistry: A Mechanistic Approach; CRC Press Taylor \& Francis Group: Boca Raton, FL, USA, 2015; p. 66.

[49] 田瑞亭. 菏泽师专学报, 2001, No. 23, 12. 